\title{
Literatura e filosofia: entre as razões do sentimento e os prazeres da inteligência
}

$\mathrm{E}$

M TEMPOS de aproximação e unificação lusófonos, com direito a reforma ortográfica, o livro Melancolia e apocalipse, estudos sobre o pensamento português e brasileiro, de Leonel Ribeiro dos Santos, merece ser conhecido do leitor brasileiro. Se bem que esse professor de Filosofia da Universidade de Lisboa dispense apresentação no meio filosófico brasileiro, já que há vários anos tem dado inúmeras contribuições em universidades no Brasil. Mas a obra em questão instiga especialmente pelo assunto, pois nela o filósofo sustenta a existência de um pensamento estético português - e também de um brasileiro -, apontando seus dilemas e especificidades, o que resulta em uma significativa contribuição para o tema atualíssimo da relação entre literatura e filosofia.

Evidentemente, o livro pode ser lido como parte dos chamados estudos culturais, na linha das análises históricas das ideias de uma época ou país; mas, na verdade, estamos diante de exercícios rigorosos de filosofia, nos quais o autor busca forjar conceitos que lhe permitam interpretar de modo qualitativo um significativo conjunto de obras de arte e de ideias estéticas. Para tal, Leonel esquivase de todo procedimento quantitativo, exaustivo ou enciclopédico ao fazer uma peculiar seleção de obras que a seu ver merecem destaque no cenário cultural. Ou seja, nesses ensaios escritos entre 1992 e 2006, o autor enfrenta os dilemas da crítica de arte de maneira constitutiva, isto é, no próprio ato da leitura, o que resulta em um método dotado de um fio condutor coerente pois baseado em princípios filosóficos e estéticos que norteiam a leitura das obras; ou seja, as leituras aqui realizadas exibem um eixo hermenêutico preciso e claro, mesmo que por vezes o autor resvale para um perspectivismo de fundo nietzschiano, recusando qualquer espírito de sistema e concorde com Fernando Pessoa no Livro do desassossego de que "os sentidos possíveis são muitos", já que os homens exprimem apenas "uma nota à margem de um texto apagado de todo".

Percebe-se tal eixo no tratamento que nos dá o autor para a relação entre literatura e filosofia. Não se trata de uma disciplina iluminar a outra, nem de recobrimento ou absorção de uma pela outra, pois aqui, definitivamente, a literatura não é o outro da filosofia. Trata-se, ao contrário, de perceber que há desde o surgimento da Estética no final do século XVIII, acentua Leonel dos Santos, um remanejamento das hierarquias no campo do conhecimento que culmina com a efetuação de uma equivalência entre as duas, de modo que tanto a literatura como a filosofia são, a partir de então, essencialmente produção e exposição de pensamento. Assim, em Antonio Vieira, Fernando Pessoa ou Antero de Quental, as obras não exibem apenas forma, estilo e aspectos retóricos, mas "substância e conteúdo de pensamento", tarefa que exige do crítico uma nova postura interpretativa. Essa necessidade foi apontada também pelo filósofo brasileiro Benedito Nunes, que há alguns anos investiga miu- 
damente a relação entre poesia e filosofia. Também ciente dessa ruptura histórica, Nunes aponta para a urgência de se pensar um novo método interpretativo, capaz de estabelecer um diálogo entre as disciplinas, mas que, considerando sobretudo a "guinada linguística", ocorrida no início do século XX, contemple o modo como se dá a produção e a apropriação histórica dos textos. ${ }^{1}$ Em que consiste, portanto, a crítica hermenêutica que encontramos em Melancolia e apocalipse? Também em uma confirmação da "guinada linguística" e na necessidade de desembocar, ao fim e ao cabo, em uma inevitável análise de discurso?

Não exatamente. As escolhas feitas por Santos recaem evidentemente em autores cujas obras possuem um forte acento filosófico. Mas, para Leonel dos Santos, toda autêntica obra de arte é uma "meditação sobre o mundo"; ou, para usar linguagem kantiana, toda obra dá a pensar. Um pensamento que não é atividade passiva, recolhimento ou distanciamento, mas gestus, intervenção criativa no mundo; o que significa, ainda em termos kantianos, que por meio da estética, tratamos sim da arte, mas, indiretamente, também da esfera da razão prática e do campo da moralidade. É o que se verifica em Antonio Vieira, no qual história bíblica, história profana, lendas, messianismo, profecias são agenciados para "responder à urgência dos fatos e situações do presente"; ou como diz, Leonel dos Santos, "em Vieira o sentido passa sobretudo pela urgência de sua realização efetiva na história” (p.105). Ou em Eça de Queiroz, que para o autor foi um crítico das soluções filosóficas de seu tempo. Ou ainda, no tom apocalíptico de Vergílio Ferreira ao constatar a crise da consciência contemporânea; e, por fim, em Agostinho da Silva, para quem o poé- tico não se confina às artes, mas afirma-se em todo fazer e criar espontâneos.

Evidentemente, adverte Leonel dos Santos, não se trata de romance de tese, ou de arte engajada, longe está disso sua concepção de arte que é sempre uma forma de exposição livre de uma ideia. Mas não há tampouco nesses estudos uma análise formal de obras, como manda o gosto contemporâneo, pois só apresentam alguns pequenos comentários sobre estilo e retórica. O fato é que as leituras realizadas pelo autor denunciam os limites e impasses do debate estético contemporâneo, situando-se por isso em outra temporalidade, especificamente no terreno da gênese do conceito de autonomia da obra de arte, nos tópicos que configuraram no final do século XVIII um campo histórico no qual a estética se constituiu pela primeira vez. Uma estética de matriz kantiana, e especialmente schilleriana, que busca superar os dualismos entre sensibilidade e entendimento, harmonizando as faculdades do homem. Uma estética metafísica, que veicula tópicos como transcendência, harmonia, absoluto, liberdade, e vê na arte uma promessa de plenitude; conceitos, por sua vez, fortemente ancorados em uma filosofia da natureza. Mas disso adverte-nos o autor, pois, ao anunciar que a obra trata do pensamento estético português contemporâneo, esclarece a curva histórica na qual insere seus estudos: "o das relações entre filosofia e literatura no pensamento europeu pós-kantiano e as poéticas e filosofias da natureza" (p.269).

Assim, não estamos especificamente no campo das filosofias da linguagem. Tal olhar nostálgico, diriam alguns, é o eixo que guia a obra. É por essa razão que em um dos ensaios mais bem realizados do livro, sobre Fernando Pessoa, Leo- 
nel trata apenas de Alberto Caieiro, por considerá-lo o único, e talvez o último, "poeta da natureza". Com efeito, aqui o vínculo entre natureza e moral jamais é apresentado por ideias abstratas, mas pela e na própria manifestação sensível. Uma natureza entendida como antídoto à modernidade instrumental e utilitária; uma natureza pensada como um processo de "depuração" às avessas, permitindo um acesso ao simples por meio dos sentidos: "eu não tenho filosofia: tenho sentidos", diz Caieiro. Ou seja, é o campo do sensível que desponta aqui em coloração crítica exigindo legitimidade diante da racionalidade irrefreável. É por essa razão que Caieiro quer as "sensações verdadeiras", o puro existir, a "paz da Natureza sem gente", "sem dentro", só "Natureza por fora", como diz em Oguardador de rebanhos, de 1912.

Se a arte é poesia pensante, por sua vez a filosofia é "poética da inteligência": "emoção acompanhada de um certo ritmo" e direcionada para a busca da verdade, diz o autor, sustentando que há um prazer também na apresentação das ideias filosóficas. Em vários ensaios, especialmente no intitulado "Razões do sentimento e prazeres da inteligência. Sobre as ideias estéticas de Antonio Sérgio", Leonel dos Santos defende que há em todo processo de constituição de uma ciência elementos estéticos, sensíveis, que enlaçam, por meio da atividade criadora, arte e ciência. Há prazer estético tanto na procura da verdade como na defesa dos valores morais, políticos ou religiosos. $\mathrm{E}$ ao recuperar o pensamento de um autor pouco conhecido como Cunha Seixas, Leonel esclarece sua tese:

Tal como Kant, tal como o seu contemporâneo Nietzsche, também Seixas parece ter assim compreendido que há uma dimensão estética da filosofia, que esta, na sua essencial tarefa de categorização do real e de sistematização categorial sob princípios racionais, responde não só a um impulso lógico para o conhecimento movido pelo sentimento de verdade, mas é impelida também, e porventura mais profundamente, por um instinto estético, pelo sentimento da beleza que é, na sua dimensão metafísica e também antropológica, uma variante da ideia e exigência de harmonia. (p.82)

Se não encontramos nesse vínculo entre natureza e moral, examinado caso a caso, uma ordem linear de razões, bem podemos localizar em uma linha sinuosa a presença do que o autor chama de pensamento português. De Antonio Vieira a Agostinho Silva, haveria uma busca por um procedimento intelectual dito português; em termos mais suaves, por uma "alma" pensante portuguesa. Não se trata de nacionalismo tacanho, ou, no polo oposto, exacerbado, mas de inserção do nacional em um movimento cosmopolita, dotado de universalidade; um nacional que não imita servilmente o ideário da moda cultural, pois o reinterpreta de acordo com a cor local; tal pensamento, que ora pode estar em Lisboa, ora em São Paulo ou no Rio de Janeiro, tampouco abandona o particular em sua indigência, valorizando-o nas obras ao dotá-lo de universalidade e clareza. Em Antonio Vieira, por exemplo, Santos vê uma escrita que, pautada pela necessidade de criar evidências, constitui-se em uma filosofia. Em Vieira há pragmatismo e liberdade; desejo e esperança, ou seja, uma intervenção prática orientada por uma visão moral do mundo. A filosofia messiânica desse jesuíta não é, assim, anacrônica, mas condizente com seu tempo, na medida em que, ao procurar reagir ao contexto 
moderno de uma primeira globalização, Vieira vislumbra Portugal como aquele país cuja tarefa é a de "pôr os mundos em comunicação" (p.13).

A revelação profética, presente em História do futuro, não é uma recaída medieval, mas uma forma de "realismo utópico": ela é uma ação política, uma intervenção fundamentada na inspiração divina, mas que é "uma resposta crítica à emergente razão política meramente pragmática e sem horizonte teleológico, que, acreditando ter por fim compreendido a mecânica dos desejos e paixões humanas, pretende reduzir estes à ordem geométrica das razões" (p.44). O que marca o tempo é o gesto profético, pois nele a verdade revela-se na história, uma história que valoriza sobretudo o futuro e não o passado. Contudo, em Vieira, trata-se sempre de um "futuro iminente", o do tempo da realização que se dá no presente. Com a devida ressalva de que tal impulso messiânico, que sobreviveu, observa Leonel, em Leibinz e na ideia kantiana de "um reino dos fins", em "Vieira é mais moral e espiritual do que político e terreno" (p.70).

Em Eça de Queiroz, Leonel encontra um olhar português sobre o mundo, um "sensato realismo crítico" que se equilibrando entre os idealismos abstratos em voga e os pessimismos niilistas, afirma-se em uma abordagem que não se afasta da vida e da ação efetiva. Em Fernando Pessoa, na figura matricial de Alberto Caieiro, como vimos, há no poeta da natureza também um crítico da civilização; mas para percebê-lo o crítico deve operar com uma compreensão histórica e filosófica do processo de formação dos heterônimos. Pois, na dicção pessoana, o que há é uma associação consciente e estratégica entre heteronímia - aliás, procedimento tradicional da literatura portuguesa -, e construção dramática; "uma complexa encenação e orquestração retórica" de modo a configurar uma das dimensões da crise da consciência moderna, e, assim, apontar para o problema filosófico da dissolução da identidade e fragmentação do Eu. Só assim, munido desse referencial histórico-retórico, seria possível perceber como os versos de Caieiro colocam sob suspeita o conceito hegeliano de totalidade, ou a ideia de uma consciência unificante absoluta, questionando radicalmente a estrutura central do conceito de modernidade. A crítica de Caieiro não desemboca em niilismo, sublinha Santos, pois postula novamente um retorno à natureza; contudo, não se trata de mais um regresso à natureza ideal, mas, agora, a uma natureza sensível, material, concreta, aquela que se descobre com os olhos, diz Santos: "Caieiro afirma com clareza sua propensão a 'ver' as coisas tais como são", seja pela rejeição dos idealismos, seja pela defesa de um nominalismo, do sensualismo, enfim do naturalismo. "Copio a natureza e não a interrogo, diz Caieiro."

É evidente que não se trata, como reconhece o próprio autor, de uma natureza impassível, captada por um olho primitivo e ingênuo, e descrita em suas minudências; mas de outra, sentimental, sintetizada, submetida ao olhar racional, e de certa forma depurada. Um sensível transformado em sentimento na obra, pois, afirma Caieiro, só diante de uma forma artística é possível "sentir a natureza". Ou, ainda, nos termos da estética intelectualizada de Antonio Sérgio, a obra é a desordem superada, "a elaboração do caos do sentimento feita pela razão".

O que Leonel Ribeiro dos Santos vai assim delineando é um perfil intelectual que se caracteriza pela busca de um equi- 
líbrio entre o sensível e o racional. Personificado no apolíneo Caieiro, o pensamento português constitui-se tendendo para a moderação, a harmonia, a simplicidade, a disciplina e o dever moral. Valores que são acompanhados de independência intelectual e afã de liberdade, pois a assimilação feita pelo pensamento português dos sistemas filosóficos em voga é sempre crítica. E jamais provinciano, por tratarse de um percurso filosófico que busca participar das tendências mais gerais da própria filosofia. A tendência de retornar a Kant, por exemplo, pode ser constatada em vários ensaios, especialmente sobre Antero de Quental. Após forte adesão ao hegelianismo, Antero de Quental opera um retorno a Leibniz, lido por intermédio de Eduard von Hartmann, e, depois a Kant, no intuito de defender especialmente o "imperativo da liberdade moral da consciência individual". Cunha Seixas, por seu turno, autor de $O$ pantiteísmo na arte, 1883, se, de um lado, apresenta certo "formalismo árido e vazio", de outro, exibe uma "genuína intencionalidade arquitetônica e um impulso para a harmonia", que em muito o aproxima dos procedimentos kantianos.

Equilíbrio, clareza, independência, harmonia: eis as prerrogativas do pensar estético português. Uma trama bem urdida entre as razões do sentimento e os prazeres da inteligência; ou, ainda nos termos de Antero de Quental, "a ideia poética sai tanto mais abundante e livre quanto mais clara e lógica é a ideia filosófica”. Será que podemos nomear tal sobriedade de uma vocação clássica? Se há uma tendência clássica na estética de Antonio Sérgio, nos pensadores da Escola Portuense, como Teixeira de Pascoaes, Aarão de Lacerda e Leonardo Coimbra, Leonel dos Santos encontra, ao contrário, uma estética neorromântica. Se há, por sua vez, no romantismo português um forte acento religioso, trata-se de uma "teologia negativa", diz o autor, na qual o conhecimento de Deus abre campo para um impulso de criação e de liberdade. Ainda, se o pensamento português acentua os campos da subjetividade e do sensível, ele é também civilizatório, como em Vieira ou em Agostinho da Silva, por encarnar como missão a difusão por outras terras do espírito de liberdade e de criação.

O pensamento brasileiro, infelizmente, é pouco analisado no livro, seja porque não se encontram nele os nomes obrigatórios, seja porque o autor entende o processo cultural pela matriz cosmopolita, e porque, assim, privilegia nos pensadores brasileiros os momentos de universalidade. Daí os estudos referirem-se apenas a Gonçalvez de Magalhães, Miguel Reale, e ao português Agostinho da Silva, quando esse esteve no Brasil. Em Gonçalvez de Magalhães, considerado "fundador" da filosofia brasileira, e autor do romântico "Suspiros poéticos e saudades", Leonel dos Santos surpreende uma obra dita de intervenção cultural, "é pelo Brasil, e só para o Brasil que escrevemos", afirma Magalhães. Todavia, não há nas ideias sublinhadas referências concretas ao cenário brasileiro, mas a repetição da mesma característica encontrada nos demais autores analisados, ou seja, a presença de um humanismo moralizador diante do avanço das ciências positivas, e também aqui a defesa de uma filosofia do equilíbrio; um ecletismo que procura corrigir ou completar "as limitações do sensualismo pelo espiritualismo, e vice-versa, realizando assim a fusão de ambos numa só doutrina" (p.113).

Já em Miguel Reale, Leonel Ribeiro dos Santos encontra um poeta e filósofo 
responsável não só por um pensamento jurídico fecundo, mas por abordar questões estéticas de modo autoral, que lhe possibilitaram a seu modo também retornar a Kant, para com ousadia corrigir "a estreiteza e o enviesamento da noção de experiência em Kant". Analisando obras como O Belo e outros valores e Experiência e cultura, Santos demonstra como Miguel Reale acentua a importância da faculdade da sensibilidade para o conhecimento de um modo geral, ao sustentar que ela não deva ser entendida como uma faculdade passiva, isto é, apenas receptiva, mas como uma faculdade ativa, responsável pelo domínio da criatividade, ou seja, da capacidade humana de criar formas e instaurar significados. "O artista é, antes de tudo, afirma Miguel Reale, um criador de modelos, de estruturas significantes como puras percepções objetivadas." Para Leonel dos Santos, a leitura original da Estética transcendental de Kant realizada pelo filósofo brasileiro possibilitouthe forjar um "novo equilíbrio" entre a reflexão clássica, a estética do século XIX e as concepções contemporâneas (positivistas, sociológicas e semióticas).

Por último, encontramos o ensaio sobre Agostinho da Silva, filólogo e poeta português que esteve no Brasil entre as décadas de 1940 e 1950, participando da fundação de várias universidades, como a de Brasília, e integrando o "grupo de São Paulo", do qual faziam parte Miguel Reale, Luis Washington Vita, entre outros. Seja aqui no Brasil, ou quando do seu retorno a Portugal, destacam-se nas ideias de Agostinho da Silva o tom provocador, a habilidade de cultivar paradoxos e a defesa da liberdade de criação, especialmente no campo pedagógico - daí a alcunha de "pedagogo da liberdade". Defesa feita sempre em método eclético, isto é, nos termos de Santos, "capaz de lidar com todos os sistemas, protagonizar em si mesmo dialecticamente os vários sistemas, miscigenando-os, transaccionandoos, fazendo-os comunicar uns com os outros, corrigindo-os e completando-os uns pelos outros, tarefa eclética esta para a qual se considerava o português particularmente dotado" (p.382).

Ora, se o que predomina no livro é o tom otimista, diante de obras que exibem equilíbrio, moderação e harmonia e de autores capazes de combinar espírito especulativo e defesa de liberdade, por que o título Melancolia e apocalipse? Adverte-nos o autor no prefácio que o título refere-se apenas ao primeiro ensaio, sobre Vieira, e não ao livro como um todo. Contudo, nos outros ensaios, especialmente sobre Vergílio Ferreira, podemos notar um contraponto ao otimismo, e supor outros autores e obras das quais Santos estaria intencionalmente se esquivando. Nesse ensaio encontramos num tom crepuscular se não a afirmação generalizada da morte da arte, pelo menos a ideia do fim do mito da arte autônoma, sugerindo que o melhor de certa forma já passou, restando apenas relembrar com nostalgia o seu momento de glória ou ansiar por um novo "renascimento". Eis o diagnóstico negativo de Vergílio Ferreira, endossado por Leonel dos Santos sobre a situação contemporânea da arte no século XX: "a arte não morre porque a filosofia ou a ciência lhe tomam o lugar, mas morre de si própria, por uma espécie de suicídio autofágico". Assim, o modernismo, nas palavras de Vergílio Ferreira, "foi uma grande noite", um experimentalismo estéril e vazio, sinalizando um momento de "afasia da velhice" da arte. Daí o resgate empreendido por Leonel dos Santos da estética antimo- 


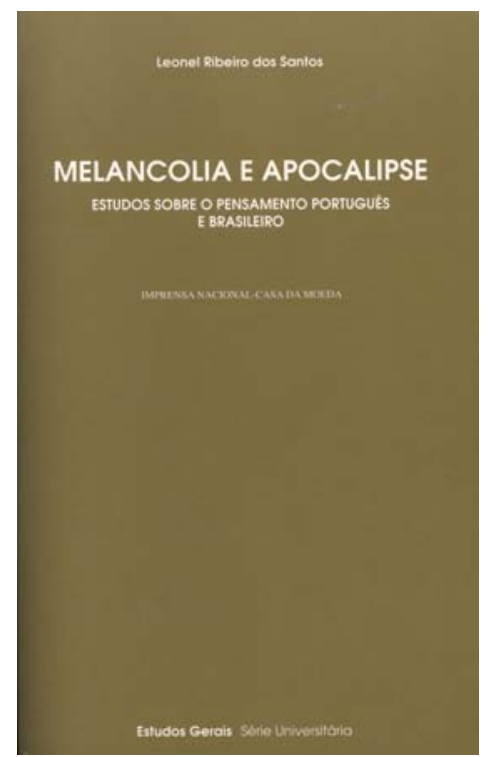

SANTOS, Leonel Ribeiro dos. Melancolia e apocalipse. Estudos sobre o pensamento português e brasileiro. Lisboa: Imprensa nacional, Casa da Moeda, 2008. 427p.

dernista de Leonardo Coimbra, a valorização da polêmica que instaura Antonio Sérgio nas páginas da Seara nova contra o irracionalismo "modernista" do "presencismo", e o fato de Alberto Caieiro, o antimodernista e crítico da modernidade que sonha com um retorno à natureza, $\mathrm{e}$ não o oposto Álvaro de Campos, ser considerado o "mais português dos poetas". Daí também o silêncio nesses estudos em torno de nomes como Almada Negreiros ou Mário de Sá-Carneiro.

$\mathrm{O}$ que significa ser clássico no século XXI? Um platonismo revisitado com direito à oposição entre aparência e verdade? Uma estética pautada pela exigência de verdade? Uma natureza sem história? Leonel, esquivando-se dos "ismos" e das "escolas", insiste na pergunta ao defender nesses estudos não se tratar nem de beletrismo ou academicismo, nem de racionalização da arte, mas de um momen- to histórico exemplar no qual o campo artístico constituía-se combinando força livre com ordem; em termos schillerianos, "perfeição combinada com liberdade". Uma ordem dada pela forma livre e não por uma forma de poder. E, se havia uma exigência da verdade nessa ordo, ela se dava no campo dos possíveis, no das conjecturas. Em outros termos, ser clássico hoje significaria afirmar que o belo é um direito, um dever-ser, ou, em termos schillerianos, que o estado intermediário de liberdade estética merece ser postulado, pois é uma disposição livre para uma intenção moral ou para o conhecimento; ou seja, o estético refere-se ao todo de nossas faculdades, a um "grau zero" em que "sensibilidade e razão são simultaneamente ativas", pois não se "comportam em face do outro como poder". ${ }^{2}$

O empreendimento hermenêutico assim situado historicamente, porém, não exigiria perguntar também pela historicidade do texto, ou seja, pela relação desse com o presente? Em Melancolia e apocalipse encontramos uma hermenêutica parcial, pois o livro aposta excessivamente na via eclética que acaba por neutralizar os contextos históricos nos quais as interpretações se inscrevem; as tensões entre arte e sociedade pelas quais ocorrem as intervenções culturais são apenas indicadas, não ficando demonstrado como efetivamente se dá o debate cultural no tempo. No lugar, sobressai excessivamente o pressuposto, aliás, da filosofia moral kantiana de valorização do aspecto moral das determinações estéticas. Mas, se dessa estética sobressai duplamente o conceito de autonomia e o de sensus comunis, ressente-se a falta nesses estudos de uma maior presença do tempo, de um sensível muita vez disforme, sem ordo, mas que possibilite à crítica interpretar, por exem- 
plo, a distância histórica entre a "melancolia" portuguesa e a alegria "apocalíptica" brasileira.

\section{Notas}

l Para Benedito Nunes (1993, p.197): “a Filosofia, que toma a iniciativa do diálogo é uma filosofia hermenêutica, a qual, por sua vez, já opera com a noção de texto, que toma por pressuposto. [...] O diálogo se efetua no plano da Crítica, isto é, no plano do conhecimento interpretativo das obras".

2 Segundo Schiller (1990, p.100): “É por proporcionar às faculdades do pensamento liberdade de se exteriorizarem segundo suas leis próprias que a beleza pode tornar-se um meio de levar o homem da matéria à forma, das sensações a leis, de uma existência limitada à absoluta".

Referências bibliográficas

NUNES, B. Literatura e filosofia. In:

No tempo do niilismo e outros ensaios. São Paulo: Ática, 1993.

SCHILLER, F. A educação estética do homem. São Paulo: Iluminuras, 1990.

Arlenice Almeida da Silva é doutora em Filosofia, professora de Estética e História da Arte no Departamento de Filosofia da Unesp, campus de Marília.

@ - arlenice@uol.com.br 